\title{
CIÊNCIAS E MATEMÁTICA EM PESQUISAS PERTINENTES ÀS CÉLULAS FOTOVOLTAICAS DE SILÍCIO NA ENGENHARIA
}

\author{
SCIENCE AND MATHEMATICS IN RESEARCH PERTAINING TO SILICON PHOTOVOLTAIC \\ CELLS IN ENGINEERING \\ Mari Aurora Favero Reis ${ }^{1}$, Tania Renata Prochnow ${ }^{2}$, \\ Agostinho Serrano ${ }^{3}$ \\ DOI: 10.37702/REE2236-0158.v39p39-49.2020
}

\begin{abstract}
RESUMO
Fundamentada no efeito fotovoltaico, através da transformação da luz em eletricidade nos semicondutores de silício, a tecnologia foi impulsionada a partir das aplicações nas Engenharias. A evolução e uso da tecnologia contribuíram para desenvolvimento de projetos sustentáveis em Trabalhos de Conclusão de Curso (TCC). Esta pesquisa teve como objetivo analisar o uso de conceitos científicos e fundamentos matemáticos, associados ao uso do silício na tecnologia fotovoltaica, em TCCs de Engenharia de uma universidade particular de Santa Catarina. Inicialmente foram localizados os TCCs que tratam de aplicações das células fotovoltaicas na Engenharia disponíveis na biblioteca virtual da universidade e publicados no período de 2010 a 2016. A metodologia empregada para estudo dos documentos foi a análise de conteúdo, utilizando-se a plataforma Mendeley como ferramenta de acesso aos conceitos científicos do silício (físicos e químicos) e fundamentos matemáticos. Os resultados do estudo demonstram que nos TCCs o silício foi retratado com conhecimentos científicos nos aspectos físicos, químicos e matemáticos, sendo que alguns demostraram excelência em todos os critérios analisados.
\end{abstract}

Palavras-chave: células fotovoltaicas; silício; Engenharia; Ciências e Matemática.

\begin{abstract}
Based on the photovoltaic effect, through the transformation of light into electricity in silicon semiconductors, technology was driven from applications in engineering. The evolution and use of technology contributed to the development of sustainable projects in the course completion work (TCC). The objective of this research was to analyze the use of scientific concepts and mathematical foundations, associated with the use of silicon in photovoltaic technology, in the work of completing the engineering course of a private university in Santa Catarina. Initially, the TCC were located, which deal with photovoltaic cell applications in engineering, available in the university's virtual library and published in the period from 2010 to 2016. The methodology used for the study of the documents was the analysis of content, using the Mendeley platform as a tool of access to the scientific concepts of silicon (physicists and chemists) and mathematical foundations. The results of the study show that in TCC Silicon was portrayed with scientific knowledge in the physical, chemical and mathematical aspects, and some showed excellence in all the analyzed criteria.
\end{abstract}

Keywords: photovoltaic cells; silicon; Engineering; Sciences and Math.

\footnotetext{
1 Doutora em Ensino de Ciências e Matemática. Professora e pesquisadora na Universidade do Contestado (Concórdia-SC). mariaurorafavero@gmail.com

2 Doutora em Ecologia - Universidade Federal do Rio Grande do Sul, professora adjunta da ULBRA/RS, vinculada ao Programa da Pós-Graduação em Ensino de Ciências e Matemática. taniapro@gmail.com

3 Doutor em Física, professor adjunto da ULBRA/RS, vinculado ao Programa da Pós-Graduação em Ensino de Ciências e Matemática. asandraden@gmail.com
} 


\section{INTRODUÇÃO}

A energia solar é mundialmente considerada fonte de energia promissora, porque é abundante, limpa e de baixo impacto ambiental. O princípio de funcionamento da tecnologia fundamenta-se no efeito fotovoltaico, conhecido como fotocondutividade, através da transformação da energia luminosa em eletricidade nos semicondutores de silício.

O uso da palavra "semicondutor" ocorreu em 1911, com o termo que surgiu do alemão (halbleiter) e foi usado para descrever uma classe de materiais (JENKINS, 2005). Mesmo considerando que os semicondutores eram conhecidos no início do século XIX, como relata o autor, seu uso tecnológico foi lento devido à falta de aplicações na Engenharia. A evolução científica, somada às aplicações na Engenharia, proporcionava a exploração das propriedades peculiares do material, antes referidas como "anômalas" e, consequentemente, motiva a atenção de muitos cientistas.

As primeiras células solares fotovoltaicas foram utilizadas na geração de energia elétrica para os satélites que orbitam nosso planeta, sendo que em aplicações terrestres eram economicamente inviáveis e, com a evolução nas tecnologias de produção, tornaram-se acessíveis (RÜTHER, 2004). Na superfície terrestre, inicialmente, as células fotovoltaicas eram utilizadas para fornecer eletricidade nos locais em que não se contemplava a distribuição da eletricidade pela rede pública. A indústria fotovoltaica cresceu rapidamente e, junto à possibilidade de uso integrado na rede (sistema on-grid), veio a possibilidade do uso da tecnologia em edificações e usinas de geração em mega escalas.

A evolução da tecnologia e aumento nas possibilidades de uso contribuíram para que o tema viesse a ser de grande relevância no Ensino de Ciências, especialmente nas engenharias. Em alguns países, como nos Emirados Árabes Unidos (EAU), que possuem larga dependência dos combustíveis fósseis, o tema "energia solar fotovoltaica" passou a ser utilizado em instituições de educação básica, ao se introduzir o assunto fontes renováveis de energia nos currículos de ciências (MOLKI, 2010). Nos Estados Unidos da América (EUA), Marta Dark (2011) afirma que os alunos interessados em carreiras na Ciência da Tecnologia e Engenharia nos próximos dez anos deveriam encontrar muitas oportunidades na área. Por conta disso, a autora propõe o uso de módulo fotovoltaico como recurso didático para despertar nos acadêmicos o interesse na Ciência, Tecnologia, Engenharia e Matemática (Science Technology Engineering \& Math STEM).

Essa realidade tem sido comum aos acadêmicos das engenharias em todo o Brasil. $\mathrm{Na}$ Universidade considerada neste estudo, a busca pelo tema tem despertado interesse na elaboração e investigação de projetos sustentáveis em Trabalhos de Conclusão de Curso (TCC).

Esta pesquisa tem como objetivo analisar o uso de conceitos científicos e fundamentos matemáticos, associados ao uso do silício na tecnologia fotovoltaica, em TCCs de Engenharia de uma universidade particular de Santa Catarina. Ainda, tal trabalho busca responder a seguinte pergunta de pesquisa: como estudantes de Engenharia referenciam o silício, a partir do uso da abordagem científica, ao investigar aplicações da tecnologia fotovoltaica em TCCs?

\section{CIÊNCIAS E TECNOLOGIA DO SILÍCIO}

\section{Propriedades químicas do silício na Energia Fotovoltaica.}

A maioria das células solares é feita de silício, pois apresentam alta eficiência e a matéria-prima para a fabricação dessas células é abundante, já que o silício geralmente é obtido através da fusão da areia de quartzo puro com carbono, com a possibilidade de manipulação na condutividade (APPLEYARD, 2006). O átomo de silício (Si) tem número atômico 14 e massa atômica 28 , portanto contém 14 prótons e 14 elétrons, característica cristalina e a forma aparente de um cubo.

$\mathrm{O}$ fato de o silício ser o segundo elemento mais abundante na crosta terrestre tem 
proporcionando expansão no uso da tecnologia, na geração de eletricidade. A produção anual mundial de células fotovoltaicas (PV) atingiu mais de 7,9 $\mathrm{GWp}$, com taxa média de crescimento anual de $40 \%$, na última década, na produção de células fotovoltaicas (SAGA, 2010). Ainda assim, a contribuição dos sistemas fotovoltaicos na produção mundial de eletricidade em todo o mundo foi estimada em menos de $0,1 \%$ : "Espera-se que a produção mundial de células fotovoltaicas totalize uma potência de aproximadamente $100 \mathrm{GW}$ até 2020, destacando-se como alternativa mais viável" (SAGA, 2010, p. 96).

Os semicondutores, que podem ser observados entre metais e isoladores, apresentam algumas propriedades importantes (JENKINS, 2005): (i) a condutividade varia quando o semicondutor é dopado com pequenas quantidades de átomos de impureza; (ii) nos semicondutores a condutividade aumenta à medida que a temperatura do material aumenta, enquanto que nos metais diminuirá com o aumento da temperatura; (iii) a condutividade dos semicondutores pode aumentar na presença de luz, fenômeno conhecido como fotocondutividade (essa propriedade será discutida na seção a seguir).

Quanto ao processo de manipulação na condutividade, o artigo The direct conversion of solar light energy into electricity, publicado na década de 1970, apresenta uma explicação simplista para a dopagem do silício (GREAVES, 1970). Nele se afirma que cada átomo de silício tem quatro elétrons na última camada de valência, que participam da ligação com quatro átomos vizinhos e, se são adicionados átomos com cinco elétrons na camada de valência, como o silício com o fósforo, quatro desses elétrons serão usados na ligação química ao silício e o quinto se tornará um elétron livre ou elétron de condução (material tipo-n). Por outro lado, se são substituídos alguns dos átomos de silício por alguns átomos com apenas três elétrons na camada de valência (comumente esse material é o boro), haverá um elétron em falta na ligação, agindo como íon positivo ou buraco (material é um semicondutor de tipo-p). Em diferentes regiões da mesma peça de silício, os elétrons do tipo-n próximos ao do tipo-p se fundem para suprir o desequilíbrio, produzindo um campo elétrico. A intensidade do potencial elétrico na região de junção é controlada pelo número de átomos de impureza do tipo $\mathrm{p}$ (receptores) e pelo número de átomos de impurezas de tipo $\mathrm{n}$ (doadores).

Em 2013 pesquisadores da Universidade Rutgers (USA) utilizaram a explicação de Greaves (1970) no ensino de Ciências, para explorar com os estudantes o processo de ligação $n-p$ nas células solares com semicondutores de silício dopado, utilizandose uma dinâmica com atividade sinestésica (RICHARDS; ETKINA, 2013).

De acordo com a teoria quântica da matéria, a quantidade de energia possuída por qualquer elétron em um material é representada em níveis de energia, sendo que o fluxo de corrente só ocorre quando os elétrons se encontram na banda de condução ou em ligação covalente (APPLEYARD, 2006). Por conta disso, segundo Appleyard, em materiais isolantes a diferença de energia é grande; nos metais as bandas de valência e condução se sobrepõem e os semicondutores apresentam baixa condutividade elétrica, sendo necessário o processo de dopagem relatado anteriormente.

Quanto ao tipo de células fotovoltaicas, estas do tipo padrão, são produzidas utilizando-se um ou mais fragmentos de cristal de silício dopado, que são conhecidos como mono e policristalino (SAGA, 2010). Saga (2010) aponta a diferença entre as células de silício: células monocristalino tem dimensão $125 \mathrm{~mm} 2$ (5 polegadas2) e as policristalinas 156 $\mathrm{mm} 2$ (6 polegadas2). Outra diferença está na eficiência energética, neste caso as monocristalinas são um pouco mais eficientes. Por fim, o autor relata como ocorre a composição e montagem das camadas do tipon (primeira camada) e do tipo-p (última camada) em uma célula de silício, de modo que ocorra a mobilização dos elétrons entre as camadas $n-p$ pelo desequilíbrio entre as cargas. 


\section{Fotocondutividade no silício à luz da Teoria Quântica}

Para compreender a origem do uso do silício na tecnologia fotovoltaica, é importante voltar às raízes dos semicondutores do silício, a partir de uma visão da História da Ciência para os semicondutores e da Teoria Quântica da Luz. No que diz respeito aos semicondutores, o primeiro estudo foi realizado por Michael Faraday, em 1833, que investigou a influência da temperatura na condutividade elétrica no sulfureto de prata, que foi um termo utilizado primeiramente por Faraday (JENKINS, 2005). No artigo de Jenkins (2005), o autor relata o estudo de Faraday, pesquisa que foi fundamental para a invenção do transistor em 1954.

A origem da Mecânica Quântica remonta à década de 1920. A historicidade em Ensino de Ciências converge para a Teoria Quântica da Luz, com destaque para a pesquisa revolucionária de Albert Einstein (1905) em Ciências (NIAZ et al., 2010). O artigo "Sobre um ponto de vista heurístico relativo à produção e transformação da luz" (EINSTEIN, 1905), que tratava do efeito fotoelétrico, atribuiu a Albert Einstein, em 1921, o Prêmio Nobel de Física. Conforme Niaz et al. (2010), tal reconhecimento teve pouca aceitação científica na época e muitos cientistas relutaram em aceitar a Teoria Quântica de Einstein, entre eles Max Planck (fundador da Teoria Quântica), que reteve a aprovação até quase 1913. Quanto ao uso do termo "fóton", este foi inventado somente em 1926 pelo químico Gilbert Lewis, ao apresentar de forma equivocada o "quantum de luz" de Albert Einstein, e o termo foi adotado pela comunidade científica quando Compton (1927) começou a usá-lo (KLASSEN, 2011).

Mais tarde, outros pesquisadores verificaram que a energia do fóton - que provém da luz e pode ser definida através da equação $E=h . v$ (onde $h$ é a constante de Planck e $v$ é a frequência da radiação) - é a energia necessária para manter "elétrons livres" e "buracos" em uma rede semicondutora (GREAVES, 1970). O efeito da luz nas células solares fotovoltaicas, no processo conhecido como fotocondutividade, tem sido explicado em muitos artigos de Ensino de Física. Neles é possível destacar que "o coração de uma célula solar é a junção $p$ - $n$ e quando o cristal absorve a luz (o efeito fotoelétrico interno), os pares elétron-furo aparecem" (RICHARDS; ETKINA, 2013, p. 579). E, ainda, os elétrons livres e furos são "varridos" em direções opostas pelo campo elétrico da junção $p$ - $n$, resultando em corrente elétrica.

As primeiras observações do efeito fotoelétrico remontam ao início do século XIX, a partir de obras de Alexandre Edmond Becquerel, Heinrich Hertz, Wilhelm Hallwachs e Joseph John Thomson. A teoria que melhor explica o fenômeno foi esclarecida por Albert Einstein em 1905 (DEMMING, 2010). A manifestação da quantização ocorre na excitação de elétrons, de modo a serem ejetados para a banda de valência do material, produzindo o que chamamos de efeito fotocondutor ou fotovoltaico.

Pesquisas anteriores demonstraram que o uso da tecnologia fotovoltaica pode ser utilizada como recurso didático no Ensino de Ciências para diferentes componentes curriculares: nos circuitos elétricos, aplicando a Lei de Kirchhoff (GFROERER, 2013); em estudos de eficiência energética (KRAFTMAKHER，2008; MOLKI， 2010; VAN SARK, 2007) e semicondutores, conforme o relatado. A Eficiência Quântica (E), por exemplo, é uma propriedade importante em um detector de luz e pode ser determinada no laboratório de Física de graduação (KRAFTMAKHER, 2008). Portanto, as tecnologias em energia renovável podem ser utilizadas com estudantes de graduação e pós-graduação, como exemplo na solução de problemas em sala de aula para demonstrar a diferença entre a eficiência e o rendimento anual da célula fotovoltaica (VAN SARK, 2007).

$\mathrm{Na}$ Universidade levada em consideração neste artigo, os acadêmicos da $4^{\mathrm{a}}$ fase dos cursos de Engenharia Civil e Engenharia Ambiental e Sanitária utilizam a tecnologia nas aulas experimentais, na disciplina de Física III. Os estudantes que participam dessas atividades desfrutam da oportunidade de rever conceitos estudados em aulas anteriores e aplicá-los em 
medições, cálculos e aplicações da tecnologia fotovoltaica.

Nesta investigação é apresentada e discutida a aplicação da tecnologia no uso de painéis solares fotovoltaicos, em Trabalhos de Conclusão de Curso (TCCs) de Engenharia. Na investigação destacam-se aspectos científicos, tecnológicos e práticos apresentados nos trabalhos dos acadêmicos, como: a) abordagem físico-química feita pelo acadêmico, em relação ao silício, na etapa de pesquisa bibliográfica; b) a aplicação da tecnologia fotovoltaica na Engenharia; c) viabilidade no uso da tecnologia (na pesquisa); d) lacunas e áreas não exploradas.

\section{METODOLOGIA DA PESQUISA}

\section{Contextualização da pesquisa}

Quanto ao foco para a seleção dos Trabalhos de Conclusão de Curso (TCC) ou monografias, a evolução da tecnologia fotovoltaica nos últimos anos, juntamente com a disseminação das possibilidades de uso desta, tem justificado a significância da aplicação contexto em pesquisas junto aos acadêmicos das engenharias. Além disso, o TCC é um requisito obrigatório e essencial à complementação do curso de graduação e, especialmente nos cursos de engenharias, a sustentabilidade energética tem motivado os acadêmicos a trabalhar com pesquisas sobre o tema.

Conforme o anteriormente relatado, foram selecionados os TCCs que tratam de aplicações do efeito fotovoltaicos, no período de 2010 a 20164, os quais se encontram disponíveis na biblioteca virtual da universidade 5. A Universidade de estudo localiza-se no interior do estado de Santa Catarina, onde possui seis Campi, com seis cursos de engenharias sendo ofertados. Foram realizadas as buscas por TCCs com esta aplicação de contexto em tecnologia fotovoltaica em todos os cursos.

\footnotetext{
${ }_{4}$ Os TCCs ficam disponíveis on-line e podem ser acessados em: http://www.unc.br/bibliotecas/.

$5 \mathrm{Na}$ universidade estudada utiliza-se como critério, para que o TCC seja adicionado ao banco de dados do servidor, que o trabalho tenha sido aprovado com média igual ou superior a 9,0 .
}

\section{Delineamento metodológico}

$\mathrm{Na}$ fase inicial, foi realizada uma pesquisa sobre as propriedades do silício, utilizando-se periódicos nacionais e internacionais que foram localizados por meio de sítios de busca como ERIC (Educational Resources Information Center), Taylor \& Francis online, portal SJR6 (SCImago Journal \& Country Rank) e periódicos CAPES. A pesquisa proporcionou um olhar a respeito da evolução científica e tecnológica empregada nas células solares de silício, hoje utilizadas na produção de energia fotovoltaica. Os artigos localizados foram adicionados na plataforma Mendeley7, a qual possibilitou localizar, através de palavraschave, as propriedades estudadas.

Posteriormente, após o download dos documentos (TCCs), o material foi organizado em um folder na plataforma Mendeley, com suas respectivas fichas individuais, compondo o corpus da pesquisa. Utilizando-se a plataforma como recurso, foi realizada uma pré-análise dos TCCs selecionados, a partir de metodologia qualitativa de análise de conteúdos (BARDIN, 2007). Para a análise, foram criados critérios e categorias para investigação de informações referentes às características científicas, tecnológicas, matemáticas e práticas (de contexto) no uso de células solar fotovoltaicas.

Uma planilha eletrônica foi utilizada para registro das informações extraídas dos TCCs e para as informações pertinentes à identificação (ano, distribuição geográfica, curso de origem dos trabalhos). Os dados eram registrados conforme apresentados no trabalho. Para as informações científicas, tecnológicas e matemáticas (abordagem química e física do silício, uso de recursos matemáticos e contexto prático no uso da tecnologia), foram criadas categorias e classificadas a fim de contribuir para a análise quantitativa com descrições analíticas. A classificação foi realizada através de critérios utilizados por Niaz et al. (2010) na

\footnotetext{
6 O portal é uma interface gráfica projetada para acessar a classificação de indicadores bibliográficos no banco de dados da SCImago Journal \& Country.

7 O Mendeleyé uma plataforma gratuita, constituída pelos componentes Desktop e Web, para gestão de referências bibliográficas, divulgando publicações e pesquisadores.
} 
análise de livros didáticos: excelente $(\mathrm{E})$, satisfatória (S), mencionar (M) e nenhuma menção $(\mathrm{N})$. Para a descrição quantitativa as classificações foram pontuadas de $0(\mathrm{~N})$ a 3 pontos (E). Para serem consideradas excelentes, as informações apresentadas no TCC, associadas a cada categoria, deveriam apresentar conhecimentos associados a estas, conforme foi relatado na seção anterior e, além disso, deveriam abranger a categoria das seguintes formas:

a) Química do silício: composição química das células; características do silício (abundância, origem, produção, dopagem etc.), tipos de silício (monocristalino, policristalino ou amorfo), propriedades semicondutoras do silício.

b) Física do silício: processos de transformação da luz em energia; efeito fotovoltaico; efeitos quânticos da luz na célula solar fotovoltaica; fotocondutividade no silício. c) Recursos matemáticos (cálculos): o trabalho deve apresentar cálculos de dimensionamento do sistema (potência, quantidade de painéis necessários); viabilidade econômica; viabilidade técnica como posicionamento do painel (ângulo de inclinação); cálculos físicos (tensão, corrente, radiação, eficiência).

\section{RESULTADOS E DISCUSSÕES}

A pesquisa de fundamentação teórica apresentada neste estudo demonstrou as possibilidades de expansão no uso da tecnologia fotovoltaica no período de 2010 a 2016, conforme já citado anteriormente. Por esse motivo, o avanço da tecnologia tem possibilitado a expansão das pesquisas em TCCs. Os dados coletados demonstram destaque no número de trabalhos publicados entre os anos de 2013 e 2016, distribuídos igualmente entre o campus de CNI e CCO (Gráfico 1).

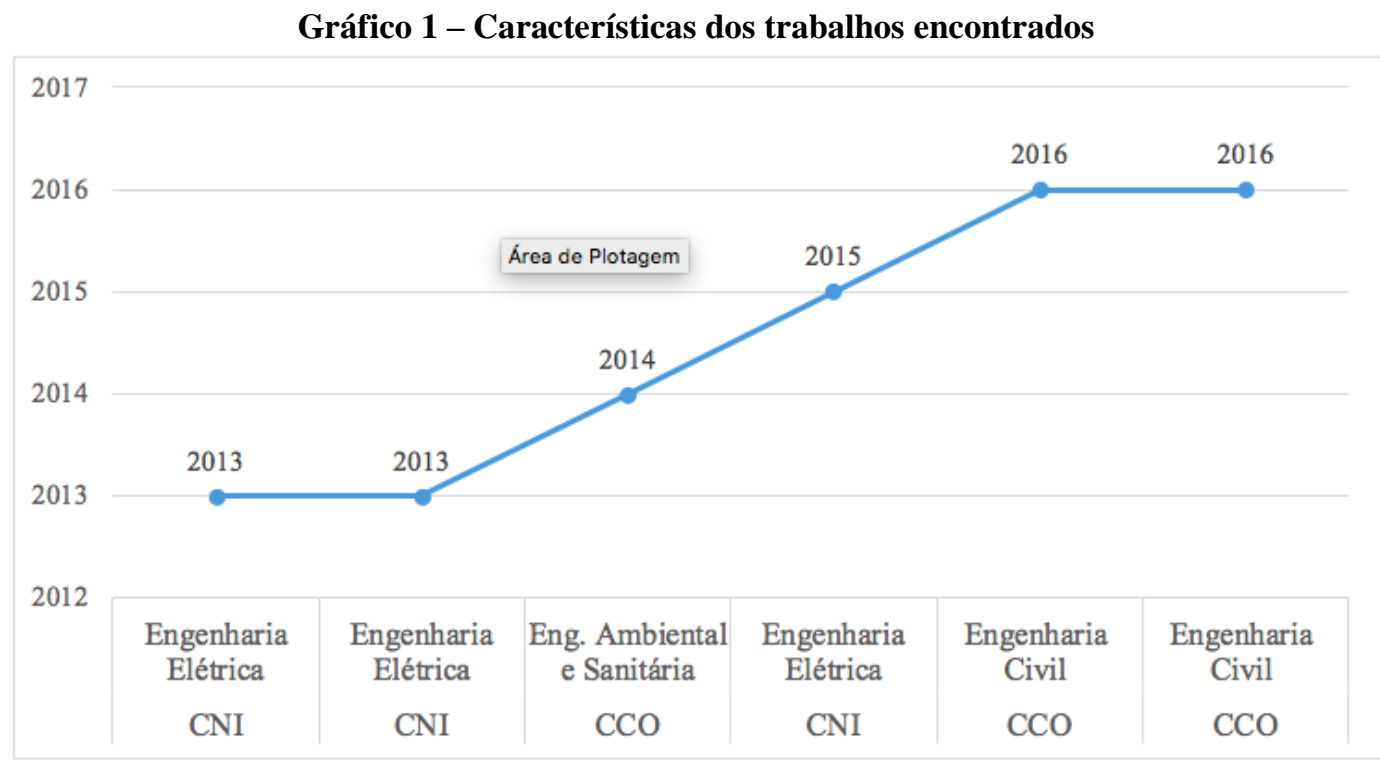

Fonte: acervo dos autores. 
$\mathrm{Na}$ busca ao acervo da biblioteca da Instituição de Ensino Superior considerada nesta pesquisa foram localizados seis TCCs que contemplam aplicações no uso da tecnologia fotovoltaica, publicados no período de 2010 a 2016 (Quadro 1).

O curso de Engenharia Elétrica defendeu o maior número de trabalhos no período estudado, com as seguintes aplicações de contexto: a) uso da energia fotovoltaica em automação residencial, com fornecimento de energia para janelas automáticas utilizando portas digitais (SCHROEDER, 2013); b) fornecimento de energia off grid para estação meteorológica (POPIA, 2013); c) alimentação de um banco de baterias para uso na transmissão de rádio $\mathrm{FM}$ da Universidade (CANDEO, 2015).

Posteriormente está o curso de Engenharia Civil, com dois trabalhos: um que estuda a viabilidade técnica e econômica para aplicação de células fotovoltaicas na cobertura dos toldos de acesso aos blocos da Universidade (SCHÖNELL, 2016) e o outro para fornecimento de energia à sistema de bombeamento de água pluvial, para cisterna de uso residencial (AMPESE, 2016).

A Engenharia Ambiental contribuiu com um trabalho, no estudo de viabilidade na mini geração on-grid (FALKOSKI, 2014). O trabalho tem sido consultado e aplicado na elaboração da proposta em chamada pública para seleção de propostas de projeto em Eficiência Energética para o ano de 2018, na Universidade do Contestado 8. A proposta de mini geração desenvolvida no TCC foi considerada na elaboração da proposta de eficiência e sustentabilidade energética para o Campus de Concórdia - SC.

Quadro 1 - Análise dos Trabalhos de Conclusão de curso de Engenharia na Universidade estudada

\begin{tabular}{l|c|l|l|c|c|c|l}
\hline Ano & TCC & Campus & \multicolumn{1}{|c|}{ Curso } & $\begin{array}{c}\text { Química } \\
\text { Silício }\end{array}$ & $\begin{array}{c}\text { Física } \\
\text { Silício }\end{array}$ & $\begin{array}{c}\text { Recursos } \\
\text { Mat. }\end{array}$ & \multicolumn{1}{c}{$\begin{array}{c}\text { Aplicação de } \\
\text { contexto }\end{array}$} \\
\hline 2013 & JSC & CNI & $\begin{array}{l}\text { Engenharia } \\
\text { Elétrica }\end{array}$ & $\mathrm{S}$ & $\mathrm{S}$ & $\mathrm{S}$ & $\begin{array}{l}\text { Em janelas } \\
\text { automáticas. }\end{array}$ \\
\hline 2013 & JOP & CNI & $\begin{array}{l}\text { Engenharia } \\
\text { Elétrica }\end{array}$ & $\mathrm{S}$ & $\mathrm{E}$ & $\mathrm{E}$ & $\begin{array}{l}\text { Em estação } \\
\text { meteorológica. }\end{array}$ \\
\hline 2014 & CFA & CCO & $\begin{array}{l}\text { Engenharia } \\
\text { Ambiental e } \\
\text { Sanitária }\end{array}$ & $\mathrm{S}$ & $\mathrm{M}$ & $\mathrm{E}$ & $\begin{array}{l}\text { Estudo de viabilidade } \\
\text { (mini geração on-grid) }\end{array}$ \\
\hline 2015 & MAC & CNI & $\begin{array}{l}\text { Engenharia } \\
\text { Elétrica }\end{array}$ & $\mathrm{M}$ & $\mathrm{M}$ & $\mathrm{E}$ & $\begin{array}{l}\text { Transmissor de rádio } \\
\text { FM da Universidade. }\end{array}$ \\
\hline 2016 & ROS & CCO & $\begin{array}{l}\text { Engenharia } \\
\text { Civil }\end{array}$ & $\mathrm{E}$ & $\mathrm{E}$ & $\mathrm{E}$ & $\begin{array}{l}\text { Estudo viabilidade } \\
\text { (Tecnologia em } \\
\text { toldos). }\end{array}$ \\
\hline 2016 & ESA & CCO & $\begin{array}{l}\text { Engenharia } \\
\text { Civil }\end{array}$ & $\mathrm{S}$ & $\mathrm{S}$ & $\mathrm{M}$ & Bomba d'água \\
\hline
\end{tabular}

Fonte: elaborado pelos autores.

Quanto ao uso de conceitos científicos e matemáticos, apenas dois trabalhos foram considerados excelentes para a representação matemática e abordagem química e física do silício (Gráfico 2). A fim de dinamizar a leitura e apresentação dos resultados, os critérios serão avaliados separadamente, em relação aos conceitos químicos, físicos e matemáticos. 


\section{Gráfico 2 - Representação dos modelos científicos e matemático do silício}

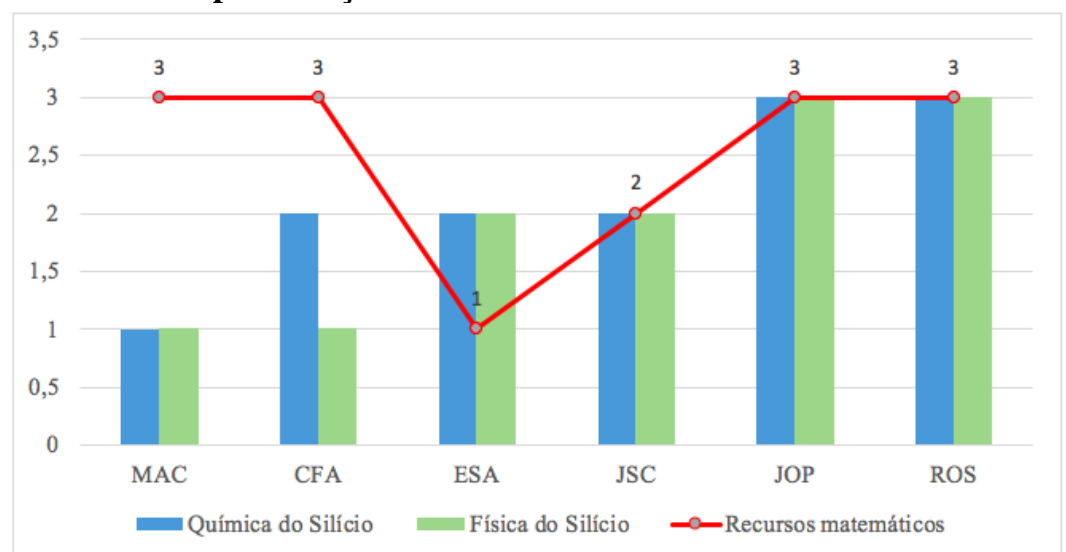

Fonte: acervo dos autores.

\section{Resultados da abordagem química do silício nos TCCs}

$\mathrm{Na}$ explicação da química do silício, é possível destacar como excelente a abordagem de pesquisa realizada pelo trabalho JOP, que apresenta de forma sucinta as características do silício bruto e as do silício dopado, com seus respectivos dopantes. Descreve, também, os tipos de células de silício e suas características. O trabalho de ROS, também avaliado como excelente, contextualiza os diferentes tipos de silício e incluí aos fundamentos teóricos, além das propriedades e a composição químicas das células, a importância do processo de dopagem para a eficiência na transformação.

Quanto aos trabalhos de JSC e ESA, classificados como satisfatórios, eles apresentam os tipos de silício e composição química, porém de forma superficial e sem a devida integração com o texto. Também não apresentam uma explicação química para a dopagem nas células de silício tal qual foi apresentada nos trabalhos anteriores. No trabalho MAC a palavra silício aparece apenas uma vez, sem qualquer conexão com as propriedades químicas do material. Por último, o trabalho CFA, que apenas menciona o termo através de uma citação textual.

\section{Resultados da abordagem física do silício nos TCCs}

$\mathrm{Na}$ avaliação desse critério pode ser destacado o trabalho ROS no que diz respeito à explicação do efeito fotovoltaico em semicondutores dopados. No contexto, o TCC aponta a reação dos semicondutores na presença da energia luminosa bem como a importância da dopagem $n-p$ na produção de corrente elétrica, conforme têm sido apresentados por uma pesquisa anterior (RICHARDS; ETKINA, 2013) e explicados no início desse estudo. O trabalho JOP também foi classificado como excelente na avaliação desse critério. Ainda, o trabalho apresenta as características físicas do efeito fotovoltaico e a importância dos dopantes na formação das cargas e, consequentemente, do campo elétrico. Observou-se, também, que esses dois trabalhos utilizaram o modelo quântico da luz, ao se reportarem aos "fótons existentes nos raios solares" (JOP, p. 14) ou às "células semicondutoras de silício [que] absorvem a energia dos fótons e convertem essa energia em eletricidade" (ROS, p. 35).

O JSC explica a produção de corrente somente pela abordagem de conceitos da Física Clássica, por exemplo ao explicar o que ocorre nas células de silício: "Quando a luz incide sobre elas, um campo elétrico é criado através das camadas, fazendo circular uma corrente elétrica" (JSC, p. 17). A predominância do modelo clássico foi verificada em outros TCCs, especialmente em MAC, em que foi encontrada uma riqueza de informações relacionadas à Física Clássica, principalmente na exposição de informações sobre a energia produzida. Por outro lado, em MAC não foram apresentados conhecimentos pertinentes à Física dos Semicondutores ou da Fotocondutividade. Por sua vez, CFA apenas menciona o efeito fotovoltaico nos semicondutores. 


\section{Resultados do uso de recursos matemáticos nos TCCs}

Nessa classificação, a maioria dos trabalhos teve a conceituação excelente. Esse fato talvez se justifique por se tratar de aplicações do uso da tecnologia em contextos específicos da engenharia. Nos Trabalhos de Conclusão de Curso MAC, CFA, JOP e ROS foram encontrados cálculos de dimensionamento, representações de modelos matemáticos, potência gerada, cálculos de custos e estudo de viabilidade econômica. Podem ser destacadas, na análise, características relevantes apresentadas nos documentos em relação a tal categoria. No estudo de viabilidade econômica o trabalho MAC, por exemplo, apresenta o estudo do retorno dos investimentos. Este é apresentado por meio de representação gráfica, de tal modo que facilita ao leitor o acesso ao resultado do estudo de viabilidade econômica. Outra característica importante na análise da categoria foi encontrada no trabalho ROS, em que são realizados estudos comparativos para tecnologias distintas, podendo ser comparados os tempos de retorno nos investimentos.

\section{CONSIDERAÇÕES FINAIS}

De acordo com o que se afirmou no início, o presente estudo teve como objetivo analisar o uso de conceitos científicos (químicos e físicos) e fundamentos matemáticos, associados ao uso do silício na tecnologia fotovoltaica, em Trabalhos de Conclusão de Curso (TCCs) de Engenharia de uma Universidade particular de Santa Catarina. A análise dos documentos restringiu-se a esse propósito.

$\mathrm{Na}$ revisão e análise dos trabalhos encontrados é possível concluir que, para os diversos contextos apresentados nos TCCs, o silício foi retratado a partir de conhecimentos científicos (químicos, físicos) e matemáticos, sendo que dois deles tiveram classificação excelente para todos os critérios analisados. Esse resultado demonstra certa concordância com pesquisas realizadas através do movimento mundialmente conhecido como STEM (Science Technology Engineering \& Math), a partir do uso da tecnologia fotovoltaica em Ensino de Ciências como, por exemplo, nos Estados Unidos (DARK, 2011).

\section{REFERÊNCIAS}

AMPESE, E. S. Uso de painéis fotovoltaicos para bombeamento de água de reuso armazenada em cisternas em edificações residenciais. 2016. Trabalho de Conclusão de Curso. Universidade do Contestado (UnC), Concórdia-SC, 2016.

APPLEYARD, S. J. Simple photovoltaic cells for exploring solar energy concepts. Physics Education, v. 41, n. 5, p. 409419, 1 set. 2006.

BARDIN, L. Análise de Conteúdo. Lisboa: Edições, 2007.

CANDEO, M. A. Sistema no break com banco de baterias carregadas por painel solar para transmissor FM da Rádio UNC. 2015. Trabalho de Conclusão de Curso. Canoinhas-SC, 2015.

DARK, M. L. A photovoltaics module for incoming science, technology, engineering and mathematics undergraduates. Physics Education, v. 46, n. 3, p. 303-308, 2011.

DEMMING, A. Solar harvest. Nanotechnology, v. 21, n. 49, p. 1-2, 2010.

EINSTEIN, A. Über einen die Erzeugung und Verwandlung des Lichtes betreffenden heuristischen Gesichtspunkt. Annalen der Physik, v. 322, n. 6, p. 132-148, 1905.

FALKOSKI, C. Estudo de viabilidade na geração e utilização da energia solar fotovoltaica. 2014. Trabalho de Conclusão de Curso. Universidade do Contestado (UnC), Concórdia-SC, 2014.

GFROERER, T. Circuits in the Sun: Solar Panel Physics. The Physics Teacher, v. 51, n. 7, p. 403, 2013. 
GREAVES, C. The direct conversion of solar light energy into electricity. Physics Education, v. 5, p. 100, 1970.

JENKINS, T. A brief history of semiconductors. Physics Education, v. 430, n. 111, p. 40, 2005.

KLASSEN, S. The Photoelectric Effect: Reconstructing the Story for the Physics Classroom. Science \& Education, v. 20, n. 7-8, p. 719-731, 2011.

KRAFTMAKHER, Y. Determination of the quantum efficiency of a light detector. European Journal of Physics, v. 29, n. 4, p. 681-687, 2008.

MOLKI, A. Dust affects solar-cell efficiency. Physics Education, v. 45, n. 5, p. 456458, 2010.

NIAZ, M. et al. Reconstruction of the history of the photoelectric effect and its implications for general physics textbooks. Science Education, v. 94, n. 5, p. 903-931, 2010.

POPIA, J. Sistema de fornecimento de energia para a estação meteorológica. 2013. Trabalho de Conclusão de Curso. Canoinhas, SC, 2013.

RICHARDS, A. J.; ETKINA, E. Kinaesthetic learning activities and learning about solar cells. Physics Education, v. 48, n. 5, p. 578, 2013.

RÜTHER, R. Edifícios solares fotovoltaicos: o potencial da geração solar fotovoltaica integrada a edificações urbanas e interligada à rede elétrica pública no Brasil. Florianópolis: Labsolar, 2004.

SAGA, T. Advances in crystalline silicon solar cell technology for industrial mass production. NPG Asia Materials, v. 2, n. 3, p. 96-102, 2010.

SCHÖNELL, R. Estudo de viabilidade para instalação de tecnologia fotovoltaica em toldos: Estudo de caso na Universidade do Contestado - Campus Concórdia. 2016. Trabalho de Conclusão de Curso. Universidade do Contestado (UnC), Concórdia-SC, 2016.

SCHROEDER, J. Janela automática utilizando portas digitais com fonte de energia renocável (painel solar). 2013. Trabalho de Conclusão de Curso. Canoinhas-SC, 2013.

VAN SARK, W. G. J. H. M. Teaching the relation between solar cell efficiency and annual energy yield. European Journal of Physics, v. 28, n. 3, p. 415-427, $2007 .$.

\section{DADOS BIOGRÁFICOS DOS AUTORES}

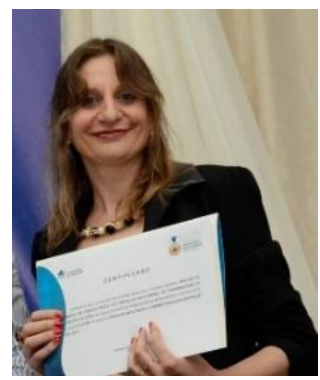

Mari Aurora Favero Reis é Licenciada em Física (1997), Mestre em Ensino de Ciências e Matemática (2004) e Doutora em Ensino de Ciências e Matemática na Universidade Luterana do Brasil (2019). É professora e pesquisadora na Universidade do Contestado. Tem experiência na área de Física Clássica, Física Quântica, Metodologia da Pesquisa e Fontes Renováveis de Energia, atuando principalmente nos seguintes temas: Ensino de Física, Energias Renováveis, Sustentabilidade e eficiência energética. 



Tania Renata Prochnow é Licenciada em Química pela PUC-RS (1969), Mestre em Ciências, ênfase em Ecologia, pela Universidade Federal do Rio Grande do Sul (1995) e Doutora em Ciências, ênfase em Ecologia, pela Universidade Federal do Rio Grande do Sul (2005). Foi professora pesquisadora do PPGECIM-ULBRA Canoas/RS (até janeiro de 2019). Tem experiência na área de Química, com ênfase em Química Ambiental, atuando principalmente nos seguintes temas: metais pesados, partículas em suspensão, poluição atmosférica, águas, microbacias, educação ambiental, ensino de ciências, formação de professores.

Agostinho Serrano Andrade Neto possui graduação em Bacharelado em Física pela Universidade Federal de Pernambuco (1993) e Doutorado em Física pela Universidade de São Paulo (1999). Atualmente é professor adjunto da Universidade Luterana do Brasil. Tem experiência na área de educação, em especial no Ensino de Ciências e Matemática, com ênfase em tecnologia de informação (TI), atuando principalmente nos seguintes temas: Investigação de Evolução Conceitual com o uso de Simulações e Modelagem Computacional, Novos Referenciais Teóricos em TI e Aquisição de Representações Científicas por meio de TI em sala de aula. 